\title{
RIGHTS AND RESPONSIBILITIES ON THE HOME PLANET
}

\author{
by Holmes Rolston, III
}

\begin{abstract}
Earth is the home planet, right for life. But rights, a notable political category, is, unfortunately, a biologically awkward word. Humans, nonetheless, have rights to a natural environment with integrity. Humans have responsibilities to respect values in fauna and flora. Appropriate survival units include species populations and ecosystems. Increasingly the ultimate survival unit is global; and humans have a responsibility to the planet Earth. Human political systems are not well suited to protect life at global ranges. National boundaries ignore important ecological processes; national policies do not favor an equitable distribution of sustainable resources. But there are signs of hope.
\end{abstract}

Keywords: biodiversity; earth; ecosystems; endangered species; fauna; flora; intrinsic values in nature; national resources; natural resources; reponsibilities; rights; United Nations.

This is the home planet. Views of Earth from space have given us an emerging vision of this place and of human life upon it. "Once a photograph of the Earth, taken from the outside is available . . . a new idea as powerful as any history will be let loose" astronomer Fred Hoyle predicted. ${ }^{1}$ That idea is one world or none, the unity and community of the home planet. Leaving home, we discover how precious a home is. The distance has helped us to get real. We have been put in our place.

Almost all the hundred or more astronauts, from many countries and cultures, have reported their awe at the sight of the whole Earth-its beauty, fertility, smallness in the abyss of space, light

Holmes Rolston, III, is University Distinguished Professor of Philosophy at Colorado State University. Mailing address: Department of Philosophy, Colorado State University, Fort Collins, CO 80523 . He presented a version of this paper at the Thirty-Ninth Annual Star Island Conference of the Institute on Religion in an Age of Science (IRAS), "Global Ecology and Human Destiny," Star Island, New Hampshire, 25 July-1 August 1992. A longer version is published in the Yale Journal of International Law 18 (1993): 251-79. (C) 1993 Yale Journal of International Law. 
and warmth under the sun in surrounding darkness and, above all, its vulnerability. The astronauts are earthstruck by their encounter with "a sparkling blue-and-white jewel ... laced with slowly swirling veils of white . . . like a small pearl in a thick sea of black mystery."

\section{Ethics on a Troubled Planet}

However, the home planet is in crisis. The two great marvels of our planet are life and mind, both among the rarest things in the universe, so far unknown elsewhere. Life is a product of evolutionary natural history, the toil and achievement of three and a half billion years. For perhaps two hundred thousand years, the human brain and hand have produced cultures superposed on natural systems. Diverse combinations of nature ${ }^{3}$ and culture have worked well enough over many millennia, but no more. Our modern cultures threaten the stability, beauty, and integrity of Earth, and thereby of the culture superposed on Earth. Behind the vision of one world is the shadow of none.

The late-coming, moral species, Homo sapiens, has still more lately gained startling powers for the rebuilding and modification, including the degradation, of this home planet. Perhaps the four most critical issues that humans currently face are peace, population, development, and environment. Human desires for maximum development drive population increases, escalate exploitation of the environment, and fuel the forces of war. Those who are not at peace with one another find it difficult to be at peace with nature, and vice versa. Those who exploit persons will typically exploit nature as readily.

We are now searching for an ethics adequate to respect life on this home planet. Earth is the only planet with an ecology, the only planet that is a home; and, on Earth, home to several million species, humans are the only species of moral agents. In the analysis to follow, we will be troubling ourselves about "rights" as an adequate paradigm for an Earth ethics, but we can already say that Earth is the only planet "right for life," and ethics will need to protect life on such a planet. Certainly it seems "right" that life continue here; life is, in the deepest sense, the most valuable phenomenon of all.

Ethics in the modern West has been almost entirely interhuman ethics, seeking to find a satisfactory fit for humans in their communities. But now, ethics is also troubled, about the troubled planet. Can we have duties concerning the natural world, even duties to the natural world? We need an environmental ethics, one that can find 
a satisfactory place for humans in the larger communities of fauna and flora.

We worried throughout most of this century-the first century of great world wars - that humans would destroy themselves in interhuman conflict. Fortunately, that fear has subsided. Unfortunately, it is rapidly being replaced by a new one. The worry for the next century is that humans may destroy their planet and themselves with it. We are turning a millennium. The challenge of the last millennium has been to pass from the medieval to the modern world, and we have built modern cultures and nations in an explosion of development. The challenge of the next millennium is to contain those cultures within the carrying capacity of the larger community of life on our home planet. On our present heading, much of the integrity of the natural world will be destroyed within the next century. To continue the development pace of the last century for another millennium will produce sure disaster. If we humans are to be true to our species epithet, "the wise species" will need to behave with appropriate respect for life. That will involve an interhuman ethics. Will it also involve an interspecific ethics, where the only moral species discovers that all the others are morally considerable? An Earth ethics, one that discovers a global sense of obligation to this whole inhabited planet?

\section{Human Rights: A Troublesome Paradigm For EARTH ETHICS}

1. Rights in Western Ethics and Law. This is the planet with biology, several billion years worth. But ethics in the West developed long before modern biology arose to describe these millennia of natural history during which life developed and the processes by which it still continues. Even after Darwinian biology appeared, philosophical and legal ethics have remained autonomous from biology, owing to a conviction that to try to derive ethics from biology commits the naturalistic fallacy. Ethics cannot be derived from biology, says the conventional wisdom, because nature itself is value free. It then seems obvious that such a value-free nature cannot be the object of human duty, for one has no obligation to protect a valueless thing.

Rather, the argument continues, ethics is for people, who value many things, including natural things. And people have rights. Humanistic ethics has come to place much weight on human rights. On the other hand, rights is a concept nowhere to be found in biology. 
Nor is it much to be found in ethics of the past. Since the origin of morality in the mists of prehistorical time, ethics has meant choosing "right" against wrong. What is right is at the core of any ethics, where right is an evaluative adjective judging behavior. Increasingly since the seventeenth century, an appeal to rights, a plural noun, is a way in which we have chosen to conceptualize the status of certain values, privileges, and possessions of persons in culture, of which it is not "right" to deprive them. A right is a person's entitlement to be treated in certain ways. A right is a valid claim that persons can make, or have made on their behalf, to have their interests or welfare taken into account. Human rights propose standards below which human life in culture ought not to fall.

In contrast to legal rights, moral rights are sometimes said to be "natural" rights - not that they can be discovered by studying nature from a scientific point of view, but that they arise from the character of human nature. Whatever biology we have in common with animals, in human nature passes over into personality. Characteristics emerge that were not present before humans appeared and do not now exist in the nonhuman world. Humans have opportunities and confront basic choices involving language, deliberation, rationality, reflective self-consciousness, responsible community membership, and so forth that are not elsewhere present.

Summarily put, human life is by nature political, and these political possibilities need defense with rights. These goods are not conventional by action of legislature or law court; they are intrinsic to the nature of personhood. Rights in fact is a better word than goods, because there are many goods (such as a new CD player) to which we have no particular innate right. Rights protect core goods, those intrinsic to personality and those most likely to be at political risk.

Rights protect certain human values thought especially important. Rights issues arise when such values need to be protected against the incursions of other humans. Everything occurs in the cultural environment of humans interrelating with other humans. "Man is by nature a political animal," said Aristotle (Politics [I, 2. 1253"]) - the animal who builds and inhabits a polis, a city. The human kind is generically an animal but specifically a citizen; that is the differentia that identifies the human essence. Hence we expect that ethics will arise to govern conduct in the polis, channelling behavior to protect the goods of human nature and culture. When we turn to nature apart from human intervention, to wild nature, which is also a component of our human environment, what then? Things changedramatically. 
2. Rights and Nature. The concept that has worked so well to protect human dignity proves troublesome when we turn to a concern for the biological world. Nature knows no rights. Nature is not civil. There were no rights over the millennia of evolutionary time-nor are there today, outside the human sector. Trees, grasses, wildflowers do not have rights, nor can they recognize the rights of others. They do not have responsibilities. They do not assert argued claims and entitlements against each other. Nor do rivers and canyons, clouds and mountains. Among the animals in the wilderness, the mountain lion is not violating the rights of the deer he slays.

Even the lion who eats a human is not violating that human's rights; he, the lion is not guilty of reprehensible behavior, for which he can be shamed or brought into court. Meanwhile, the human, in relationships with other humans, does have a right to be rescued. If National Park Service officials made no effort to rescue a human from a cougar attack but only stood by and watched, they would be morally as well as legally reprehensible. But it would be the humans who were faulted, not the lion. Rights go with legitimate claims and entitlements, but there are no titles or laws that can be transgressed in the wilderness. Nature is amoral, though perhaps valuable.

Rights for rocks, rivers, plants, animals are comedy, because in nature the concept of rights is inappropriate. John Muir once lamented, "How narrow we selfish, conceited creatures are in our sympathies! how blind to the rights of all the rest of the creation!" (Muir 1916, 98). We can appreciate the rhetoric, the poetry, the lament, but can we take seriously the rights of the alligators, the rushes, the lilies, the ferns, the swamps in which Muir was reveling?

3. Animal Rights? Arne Naess says of animals that "in principle each of them have the same right to live and blossom as we and our children have" (Naess 1984, 266). A sign in Rocky Mountain National Park urges visitors not to harass the bighorn sheep: "Respect their right to life." Tom Regan argues, at great length, "the case for animal rights" (Regan 1983). Perhaps animals have rights? But the concept is problematic and becomes more so the further one moves into the alien animal world. We speak with some plausibility of the "mammal rights" of chimpanzees and dolphins, of near relatives in nature who seem almost to have personalities. But one finds it more difficult to speak of the rights of birds or of bats (the latter are mammals too), and we are troubled to speak of any at all in oysters and insects. Moving across the spectrum (the species) of animal being, the concept of rights translates from human affairs to human-animal relations less and less well. 
Regan claims that we should not arbitrarily restrict rights to persons. Still, animal rights are not natural in the sense that they exist in spontaneous nature. Rights readily attach to values we wish to protect in persons but transfer uncertainly to wild animals. A cultural discovery is being deployed in the attempt to make this fit appropriate behavior toward wild animals. But since the proposed objects of moral concern, wild animals, have nonpersonal values; much of what we wish to protect in humans does not exist in animal nature.

It is really more natural to say that animals have goods (or, more technically, utilities). Although rights do not exist in wild nature, goods do. In sentient animals goods involve health, or interests satisfied-briefly, their welfare. Since that is so, perhaps what we really want is a vocabulary of value. Animals enjoy values intrinsic to themselves, their own welfare. When humans arrive, appropriate respect for those values generates an ethics. Rights is a noun and can look like the name for something that an animal or a human has, in addition to hair, teeth, skills. But there is no reference to anything biologically present. A right is more like money or status. Such things are subjectively, sociologically real; they are used to protect values that are inseparably entwined with personality. We may try to stretch such rights and project them out of culture onto wild nature, but this move does not work convincingly if we stray far from analogical contexts. The concept breaks down because nature is not culture.

Environmental ethics, thus, uses rights, as a term of convenience; the real convictions here are about what is right. The issues soon revert to evaluations of right behavior, and we are well-advised to dispense with the noun rights, which does not attach to animals in the wild. We should use only the adjective right; it is summoned when moral agents encounter nature and find something valuable already there. The concept of rights is sometimes convenient rhetoricallybut it is in principle unnecessary.

Rights is a political concept; it refers to the human animal who lives in a polis but not to the nonpolitical animals. Rights protect life-but life in culture where persons desire liberty for the pursuit of happiness. Persons have life choices to make, opportunities to develop, careers to choose, investments to undertake. These are the options of culture, which rights need to protect. But wild animals, if they also have their freedoms, are what they are genetically, without cultural options. The concept of rights has proved among the most powerful of the political and ethical concepts of recent centuries, as a way of protecting personal dignity. Alas, we find that the paradigm that works so well in culture cannot be successfully extrapolated to nature. 
4. Human Rights to Nature. There is, however, an application of the rights concept that is valid and increasingly vital. We can apply human rights to human needs for an environment with integrity. If there are any such things as natural rights, privileges that we possess just by being born on Earth, the right to nature is foremost among them, a sort of birthright. Other humans have no right to dispossess persons of this natural heritage. A right to nature would include protection of the air, soils, waters, and essential biological processes, maintenance of the sustainable productivity of the land, preservation of biodiversity, protection from toxic substances, and perhaps access to public lands and to natural resources essential for life.

Claiming such a right is an assertion about nature, not culture. However, it is not an assertion directed to nature, the source of these goods; rather, it is directed to other humans. Rights claims are still political claims. The claim of a right to nature is emerging now; previously it was little acknowledged because little threatened. The claim seems perfectly consistent with previous views of human rights, which have protected the core values of a high-quality human life; for humans have a right, not only to the basic life support in their natural environments but also to the quality thereof.

We do want to be conceptually clear, however. This right to a natural environment is not something that it is in the power of the state to convey or enforce, should we mean that the state can order nature to owe us these goods. Nature is not a political good. The central goods of the biosystemic Earth were in place before humans arrived. Humans have come to possess what has been naturally given. The only right to a natural environment that the state can convey is to protect the natural givens from degradation by other humans. It can protect, permit, conserve, and constrain human interactions with nature. In this respect the right to nature parallels the right to life, for the state does not convey life either; it only safeguards this natural given. The right to life is unlike the right to vote, to trial by jury, to possession of property, to national defense, or to a minimum wage.

This most recent use of the prevailing rights paradigm is an important one. Be aware of the fact, however, that we are protecting Earth by adding on to an old paradigm, rights theory, rather than facing up to the larger epistemic crisis. We are adjusting the periphery of the old theory rather than looking for a new one. It is true that in both ethics and law we have fought long and hard simply to get human rights acknowledged; what we probably do not need now is a shift of paradigms. So by all means, let us affirm, among other human rights, a right to high-quality environment. 
But such a "right to nature" is a right within culture; that is, it is a claim we can make against intrusions by other humans that put a healthy environment in jeopardy. Aggregating these claims at the global level, we might say that we humans have a right to this home planet. That would not mean, again, that humans have some kind of claim against Mother Nature, for nature is no moral agent. We may say that the Earth system and its ecosystems are valuable, and mean, not simply that we value them, but that they are able to produce all the values achieved in natural history. But there is no right to be claimed against nature for these processes and products. Nature is prolific, but not responsible.

\section{RESPONSIBILITIES: RESIDENTS ON A VALUABLE EARTH}

But we humans are responsible for that prolific nature, not in the sense that we have produced it; to the contrary, nature produced us. Our responsibility is to protect what we have been given on the Earth on which we reside; and that, at the most fundamental biological level, is life. A responsibility now is a duty that arises, owing to our inherent moral capacity, when we gain the power to threaten existing or potential value in the world. Responsibilities of the moral kind are found only in Homo sapiens; plants and animals do not have such responsibilities, much less do rivers and mountains. With this recognition of responsibilities, we must ask what values are found in the natural world (a better question than what rights are there), and locating such values will, in persons of conscience, generate specific duties. We must, to be sure, also use values in nature as resources for our own values in cultural and personal life, but we cannot be responsible always and only to exploit values found in the world in our own self-interest.

When humans encounter living things, not just animals but plants as well, they find themselves in the presence of something vital, something pursuing its own values, and humans become responsible for their own behavior in regard to these living things. A moral agent deciding his or her actions ought to take account of the consequences for other evaluative systems. We do have a responsibility to protect values, where they are present and at jeopardy by our behavior. We will, of course, have to trade the human values that we pursue against the biological values that we encounter, and this will require adjudicating values, but that is the essence of moral decision.

At the species level, responsibilities increase. In immediate encounter, one meets only organismic individuals, not species. But 
over generations species exist and are as real as individual plants or animals: specific forms of life historically maintained in their environments over time. A respect for life finds it appropriate to attach duty dynamically to the specific form of life. The species line is the dynamic living system, the whole, of which individual organisms are the essential parts. The species too has its integrity, its individuality, its "right to life"(if we must use the rhetoric of rights). The appropriate survival unit is the appropriate level of moral concern. Indeed, it is more important to protect this species vitality than to protect individual integrity. A shutdown of the life stream on Earth is the most destructive event possible.

With ecosystems, responsibilities continue to rise. "A thing is right," urged Aldo Leopold "when it tends to preserve the stability and integrity of the biotic community; it is wrong when it tends otherwise" (Leopold [1949] 1968, 224-25). He is pleading for what he calls a "land ethic." Nothing lives on its own; everything lives in relationships to other things. The ecosystem outside the organism is as vital as the biochemistry within. So if we are defending life, we must defend the whole context of life. A moral agent ought to find that such ecosystems are satisfactory communities to which to attach duty. Our concern now is the system of life as a whole, not so much individuals, or even species, as ecosystems, in which plants, animals, and humans have their well-being.

Our concern ought to be for the fundamental unit of survival, and this is not so much individual animals and plants, nor even species, but ecosystems as dynamic communities persisting and evolving over time. That is what is most valuable biologically, and that is where responsibility must focus.

There is one level more, the global level. Environmental ethics is not complete until we have an Earth ethics. People on a landscape may speak about the "land," and Leopold's vision was of a land ethic. But in our shrinking world, the "land," the good earth, is really the home planet, the good Earth. We need an ethical vision that counts things outside the human circle. Perhaps humans should find a place in an encircling Earth? We may not want to say that animals, plants, species, ecosystems, or Earth have rights, but neither do we think humans have a right wantonly to destroy these valuable things. In an ethic of respect for life, the appropriate level of moral concern is the appropriate survival unit. The planet is that ultimate survival unit.

Now we are getting a change of reference frame. No longer does it seem that humans count alone, with everything tributary to them; humans count as residents on this majestic planet. At this scale of 
vision, if we ask what is principally to be protected, the value of life is as good a word as rights to life, and a more comprehensive category. Human responsibility on Earth is as good a word as human dominion over Earth, indeed a better one, for it captures what dominion originally meant in the famous Genesis charge to Adam and Eve, or what it ought to mean, a stewardship or trusteeship over something entrusted into one's care. Residence is as needed a word as citizenship, if the reference is to Earth, the home planet, as well as to polis, our home "town" or political community.

\section{Political Citizens and Fragmented RESPONSIBILITY}

Superimposed on this morally deep natural world is the world of human culture, and this is a politically fragmented world. There is one Earth; on it are 170 sovereign nations. "The Earth is one but the world is not" (World Commission on Environment and Development 1987, 27). True, the one Earth is plural in its landmasses and supports myriads of ecosystems, diverse species, diverse peoples. Still, the divisive troubles arise among the world states. The national sovereignties are not well adapted for harmonious relations with the Earth commons. The "rights" of nations, and "rights" as claimed by citizens of these political states, are not well aligned with the ecology and geography of the planet. Our citizenship is not synchronized with our residency.

1. Nation States and Natural Resources. Many of Earth's natural resources, unevenly and inequitably distributed, have to flow across national lines, if there is to be a stable community of nations. Natural resources lie where they lie by nature. National boundaries were drawn for political reasons, with minimal attention to natural resources, and nearly all drawn before many of the modern essential resources were resources at all: coal, electric power, uranium, copper or iron ore. For example, petroleum on Earth is highly concentrated; one quarter of the known reserves are in Saudi Arabia, and more than half in the Middle East. The need for petroleum, however, is dispersed over nations around the globe. But the divisions of nation states, only accidentally related to the location of this most valuable natural resource, only compound the problem.

Few, if any, nations are self-sufficient in all of the natural resources that they need or desire, and many are quite deficient. Wars result. People are fighting over what they think they have a right to: a sufficient share of Earth's natural goods so that they can flourish as 
persons who seek life, liberty, and the pursuit of happiness. That sounds plausible, since there is a right to nature. But people are also fighting as citizens of nations that have economic policies and political agendas, demanding loyalties in support. Their access to natural resources comes filtered through political units that are not formed, or continued, with these ecologies in mind. They want resources, but the political alignments can often mean suboptimal and unjust solutions. Natural resources have to become national resources, and "nationalizing" natural resources can be as much part of the problem as part of the answer.

A huge number of people are undernourished. People have a right to adequate food. Yet it is a recurrent pattern that, in the midst of starvation, there is food available either in the area hit, in neighboring territories, or in the global community at large. But for political or economic reasons such food cannot flow to those who are hungry, and once again the social institutions thwart what could be a just distribution of the produce of an Earth commons. As a result, the environment will be further degraded, and the downward spiral continues.

2. International Responsibility and Global Ethics. The one Earth has no one government, and to establish one seems impossible in the foreseeable future. Since sovereign nations are unwilling to cede any sovereignty to a world government, commons issues have to be negotiated in a political system where nations are defending the rights of their citizens, but the fragmented system prevents an integrated, global solution. Cooperative action is difficult where there is little opportunity to regulate and police. The institutions that can take action internationally on global-scale environmental problems are weak. We are still looking for an ethics by which the global commons can be fairly shared in ways that make ecological sense. When nation states are politically operated as if geography and ecology were irrelevant, there will be disaster for both nations and nature. Such nations are essentially misfits on their landscapes.

Keeping each nation oriented to global perspectives is a major role of the United Nations. Since the United Nations is not a sovereign state, its appeal must be largely persuasive, negotiatory, ethical-based on rights and responsibilities more than on military force or political power. Its laws are soft laws, but they are aspirational and can orient nations. The United Nations Environment Programme played an important role in negotiations leading to the 1987 Montreal ozone protocol. Nevertheless, national sovereignties have often tended to constrain the effectiveness of the United Nations 
as an advocate of the global commons. Concern is ample, but cooperation is elusive because nation states defend the interests and rights of their own citizens. Nation is thus cast against nation; often the developed nations and the developing nations align in rival groups. The question of responsibilities to Earth is addressed only subsequently, if at all.

Lest any think that all the problems are caused by developing countries demanding their rights, it should be remarked that the United States has been quite unyielding of its national interests and those of its citizens. A controlling interest in national sovereignty and welfare alone may prevent an Earth ethics by the fallacy of misplaced community. The nature and character of the communities to which one belongs are thus mistaken, and such disproportionate emphasis is given to some that one becomes blind to others. With the wrong premises about community, the wrong conclusions and inappropriate actions follow.

The United Nations Conference on Environment and Development, in Rio de Janeiro in June 1992, was convened in the hopes of reaching more environmentally responsible agreements internationally. Almost every nation on Earth was represented there. Once there was hope for four international conventions: (1) Forests, (2) Biodiversity, (3) Biotechnology, and (4) Climate, though only two survived the negotiating process, and then in greatly weakened form. Biological resources were taken to be national possessions in dispute, rather than an Earth commons to be shared; it was difficult to find a fabric in which to share them. On the climate convention, the other major industrialized nations were all agreed to setting explicit national targets. The principal impediment remains United States unwillingness to accept the need for setting specific $\mathrm{CO}_{2}$ reduction targets. National rights obscure global responsibilities. National sovereignties divide us when we need deeper solutions, respecting the larger communities of life on Earth. We are quick to assert our rights; we are slow to face our responsibilities.

3. National Citizens and Native Residents on Earth. Real community does not yet exist at world levels; nevertheless humans live on only one Earth, and our powers operate at global ranges. An opportunity from here onward, indeed a necessity thrust upon us, is to see Earth globally, to see ourselves as Earth residents with transnational interests. From the perspective of a nation state, when we hear the word international, we think at once of domestic and foreign. But with the word global, there is no domestic and foreign-we are all natives. At that level, we are not citizens of a nation but residents of Earth. 
The animal who builds a polis still inhabits an oikos, a whole world; humans have an ecology. We are natives, naturally born on Earth, before we are nationals, citizens of a political state. The human is first and always an Earthling.

The natural and the cultural on Earth have entwined destinies. Across great reaches of geological time, there were no humans on Earth; Earth was entirely a natural system. Earth remains a vast natural system. But for several thousand years Earth has increasingly supported cultural systems, and, in the last few centuries, these cultural systems have grown exponentially. Today cultural systems, organized as national systems, press Earth's natural systems to their carrying capacities. In such situations, the myriad sovereign states can make cooperation difficult.

But there is another side to the story. The threat to natural systems at the planetary level can in fact produce consensus, because now nations have a common interest that is entwined with the integrity of natural systems on the planet. The rights we claim have to be integrated with our responsibilities at the planetary level.

The Earth is one; its cultures are myriad. In a way, that is welcome, for diversity is part of the richness of Earth. Cultural diversity is a good thing, just as natural diversity is a good thing. Many environmental problems are regional and do not need global solutions-but not all problems, and not in some critical issues. Diversity can be divisive. The diversity of cultures does not make it easy to reach common accord, even when such cultures have a common interest in maintaining the natural systems that support them.

Our national loyalties and cultural identities can assist in our task, but they can just as often get in the way. The essential problem is that power is decentralized into national and subnational political units that may have little or no intelligent relationship to geography and ecology, while solutions are needed that integrate into systemic, global levels on a whole Earth. Regionalism in environmental policy can be a good thing, but only if the regional focus is as geographical and ecological as it is political, and only if the region knows its global connections. The operative values tend to become fragmented, political, economic; the needed values are global, ethical, and ecological.

The view from space gives us that vision, but we have yet to make it operational. The view from space eliminates boundaries; Earth is a seamless, dynamic whole. Two Arab astronauts have sensed this: "The first day we all pointed to our countries. The third or fourth day we were pointing to our continents. By the fifth day we were aware of only one Earth." "From space I saw 
Earth-indescribably beautiful with the scars of national boundaries gone."

Once the mark of an educated person could be summed up as civitas, the privileges, rights, responsibilities of citizenship. People ought to be good citizens, productive in their communities, leaders in business, the professions, government, church, education. That was the responsibility that went with your rights. But the mark of an educated person is today, increasingly, something more. It is not enough to be a good citizen, it is not enough even to be international, because neither of those terms has enough nature or earthiness in it. Citizen is only half the truth; the other half is that we are residents dwelling on landscapes. We are natives on Earth. Our responsibility to Earth might be thought the most remote of our responsibilities; it seems so grandiose and vague beside our concrete responsibilities to our children or next-door neighbors. But not so: the other way round, it is the most fundamental, the most comprehensive of our responsibilities. We can hardly be responsible to anything more cosmic-unless perhaps to God.

\section{ETHICS ON THE HOME PLANET}

An ethics about dirt? That is sometimes taken to be the ultimate reductio ad absurdum in environmental ethics. Put like that, I suppose, we have to agree. A clod of dirt, just some earth (spelled with the lower case $e$ ) has no intrinsic value, nor do we have duties to it. But when we go from earth to Earth, from dirt to the prolific planetary system of which it is part, perspectives change. Earth is Mother Earth, the womb out of which we come and which we never really leave. Dealing with an acre or two of real estate, perhaps even with hundreds or thousands of acres, we can think that it belongs to us. But on the global scale, Earth is not something we own. Earth does not belong to us; rather we belong to it. We belong on it. The question is not of property, but of community. The vision of human life we ought to seek is not the maximum exploitation of Earth as a big property resource; it is that of valued residence in a created community of life.

In that sense, an Earth ethics is not the reductio ad absurdum of silly and peripheral concern about chipmunks and daisies, extrapolated to rocks and dirt. To the contrary, it elevates to ultimacy an urgent world vision. Perhaps there is a God above, and this marvelous Earth creation may witness to that God, but meanwhile what cannot be doubted is that on this enthralling Earth we live and move and have our being. A century ago, a call for community was typically phrased 
as the brotherhood of man and the fatherhood of God. Now such a call must be more ecological, less paternalistic, a call for appropriate respect for this home Earth.

It was feared by some that the space flights, reaching for the stars, would be an act of human arrogance, hubris in extreme, more of the conquest and dominion by Homo sapiens that have already ravaged the planet. But people responded unexpectedly. The haughty, the high, and the mighty of spirit failed to result from the flight into space. Rather humility-from humus, meaning "earthy," also the root of human-was the dominant experience. Perhaps that is a truth in the beatitude: "Blessed are the meek, for they shall inherit the Earth." For Earth is indeed a planet with promise, a promised planet, and we humans have both the right to share in and the responsibility to help to keep that promise.

\section{NOTES}

1. Astronomer Fred Hoyle, quoted in Kelley 1988, inside front cover.

2. Edgar Mitchell, quoted in Kelley 1988, at photographs 42-45.

3. Nature as used here typically refers to natural forces operating independently of human deliberative and technological activity-that is, spontaneous or wild nature. The processes of culture interrupt such nature and are artifactual. There is spontaneous nature within us (our biochemistries), but the distinct human nature (characteristic property) is to build cultures, redirecting the course of wild nature to human utility (growing crops, building houses). As Aristotle put it (in Politics), humans build a polis, a political community with its transmissible culture and technology. Humans are the animals whose nature is to be artificial, or cultured.

In another sense of natural, nothing that humans do in culture breaks any laws of nature (unless there is the supernatural); we simply rearrange natural forces to our benefit. In this sense, Manhattan is as natural as Yellowstone Park. But this sense is not helpful in the present analysis, since Earth destroyed by humans would be as natural an event as Earth with several billion years of natural history before humans arrived, or Earth carefully conserved by humans thereafter. 82 .

4. Sultan Bin Salman al-Saud, from Saudi Arabia, in Kelley 1988, at photograph

5. Muhammed Ahmad Faris, from Syria, in Kelley 1988, at photograph 76.

\section{REFERENCES}

Aristotle. Politics. 1988. Edited by Stephen Everson. Cambridge and New York: Cambridge Univ. Press.

Kelley, Kevin W., ed. 1988. The Home Planet. Reading, Mass.: Addison-Wesley. Leopold, Aldo. [1949] 1968. A Sand County Almanac. New York: Oxford Univ. Press. Muir, John. 1916. A Thousand-Mile Walk to the Gulf. Boston: Houghton-Mifflin.

Naess, Arne. 1984. "A Defense of the Deep Ecology Movement." Environmental Ethics 6: $265-70$.

Regan, Tom. 1983. The Case for Animal Rights. Berkeley and Los Angeles: Univ. of California Press.

World Commission on Environment and Development. 1987. Our Common Future. New. York: Oxford Univ. Press. 